\title{
Daily Affect and Female Sexual Function
}

\author{
David A. Kalmbach, $\mathrm{PhD}^{\star \dagger}$ and Vivek Pillai, $\mathrm{PhD}^{\ddagger}$ \\ *Department of Psychiatry, Sleep and Chronophysiology Laboratory, University of Michigan, Ann Arbor, MI, USA; \\ ${ }^{\dagger}$ Department of Psychology, Kent State University, Kent, OH, USA; ${ }^{\ddagger}$ Sleep Disorders \& Research Center, Henry Ford \\ Hospital, Detroit, MI, USA
}

DOI: $10.1111 / \mathrm{jsm} .12712$

\section{A B S T R A C T}

Introduction. The specific affective experiences related to changes in various aspects of female sexual function have received little attention as most prior studies have focused instead on the role of clinical mood and anxiety disorders and their influence on sexual dysfunction.

Aim. We sought to understand the transaction between daily affect and female sexual function in effort to provide a more nuanced understanding of the interplay between affective and sexual experiences.

Methods. The present study used a 2-week daily diary approach to examine same-day and temporal relations between positive and negative affect states and sexual function in young women.

Main Outcome Measures. We examined the unique relations between positive (i.e., joviality, serenity, self-assurance) and negative (i.e., fear, sadness, hostility) affects and female sexual response (i.e., desire, subjective arousal, vaginal lubrication, orgasmic function, and sexual pain) while controlling for higher order sexual distress, depression, and anxiety, as well as age effects and daily menstruation.

Results. Analyses revealed different aspects of both positive and negative affects to be independently related to sexual response indices. Specifically, results indicated that joviality was related to same-day sexual desire and predicted increased desire the following day. This latter relation was partially mediated by sexual activity. Further, greater sexual desire predicted next-day calmness, which was partially mediated by sexual activity. Notably, fear was related to same-day subjective arousal, lubrication, orgasmic function, and vaginal pain, whereas poorer orgasmic function predicted greater next-day sadness.

Conclusions. These findings describe the manner in which changes in affect correspond to variations in female sexual function, thus highlighting the inextricability of mental and sexual health. Further, these findings may offer insight into the progression of normative levels of affect and sexual function as they develop into comorbid depression, anxiety, and sexual dysfunction. Kalmbach DA and Pillai V. Daily affect and female sexual function. J Sex Med 2014;11:2938-2954.

Key Words. Positive Affect; Negative Affect; Female Sexual Function; Hierarchical Linear Modeling

\section{Introduction}

$\mathrm{P}$ revious investigations have demonstrated that poor emotional health commonly co-occurs with female sexual difficulties [1-3] and increases the risk of developing a sexual dysfunction [4]. This large body of research highlights the importance of affective experiences in female sexual functioning. As much of the current literature has focused on sexual difficulties in the context of psy- chiatric illnesses, an abundance of the extant evidence has focused on clinical conditions, such as depression and anxiety, as precipitating and perpetuating factors of sexual dysfunction [1,5], much to the exclusion of more normative affect states. Yet, to better understand the psychogenic influences of female sexual response and dysfunction, it is important to examine how normative affective experiences correspond to sexual function in women's daily lives. As mood and anxiety disorders 
are, at least in part, the product of chronically and severely dysregulated emotion, examining the interplay between normative affect and sexual response may not only offer insight into the specific affect states relevant to sexual response but also improve our understanding of how normative affect and sexual functioning coevolve into more clinically significant states or disorders. To address this gap, the present study employed a repeated measures design to examine the relations of normal variations in daily affect (i.e., joviality, selfassurance, serenity, sadness, fear, and hostility) and indices of sexual function (i.e., desire, subjective arousal, lubrication, orgasmic function, and sexual pain) in a sample of young women.

Normative affect, as opposed to clinical mood or anxiety disorders, refers to normal, "everyday" emotions, such as happiness and fear [6], which change in response to our daily experiences. Normative affect states are less stable and severe than pathological mood states. To illustrate, a person may occasionally feel sad or fearful, but not suffer from a mood or anxiety disorder. Affect consists of both positive and negative states. Positive affect refers to the degree to which a person feels happy, enthusiastic, or confident, whereas negative affect refers to an individual's feelings of distress and unpleasantness, including sadness, fear, and anger $[7,8]$. Although affect includes both positive and negative states, these experiences do not constitute opposite ends of a continuum. Rather, positive and negative affects are related, yet unique, constructs [6-9] shown to be differently related to mood and anxiety disorders such that low positive affect (i.e., anhedonia) is unique to depression, whereas high negative affect is characteristic of both depression and anxiety [10]. Moreover, positive and negative affects have been shown to be independently related to a number of health outcomes, including sleep disturbance [11] and cardiovascular, gastrointestinal, and immunological health $[12,13]$.

Although much of the research on emotional health and sexual function has focused on sexual problems in the context of psychopathology (e.g., Laurent and Simons, and Atlantis and Sullivan $[1,5])$, recent investigations have shifted some of the attention to the influence of positive and negative trait affects. Oliveira and Nobre [2] found that both positive and negative trait affects constituted vulnerabilities to overall sexual dysfunction, which was partially mediated by depressed and anxious mood states. In focusing on female sexual desire, Peixoto and Nobre [3] similarly found that both positive and negative trait affects constituted vul- nerabilities to difficulties with female sexual desire and that depressed mood partially mediated these relations.

Despite this recently growing body of research, a number of gaps exist in our understanding of the transactional processes between affect and sexual function. Notably, past investigations have placed greater emphasis on interindividual differences (trait) rather than intraindividual change (state). Oliveira and Nobre's [2] and Peixoto and Nobre's [3] showed that women with lower trait positive affect and higher trait negative affect also reported greater sexual dysfunction and lower desire compared with women with high-trait positive mood and low-trait negative mood. While these finding are important in identifying interindividual vulnerabilities to sexual dysfunction, these investigations fail to account for the intraindividual variance in the relation between affective experiences and sexual function across time.

A number of studies have shown changes in female sexual response following induced positive and negative affects. Evidence suggests induced positive affect allows for higher levels of desire [14] and subjective arousal $[15,16]$ in response to erotic stimuli, although other evidence has not supported relations between positive affect and arousal or genital response $[15,17]$. In comparison, the relation between negative affect and female sexual response is even more mixed. A number of experimental studies have shown that induced negative affect is related to greater levels of genital response to erotic stimuli, but is unrelated to subjective arousal $[14,18]$. These findings are intriguing as they are not consistent with evidence supporting relations between trait negative affect, depression, anxiety, and poorer overall female sexual response $[1,2]$. However, it is worth noting that, though a useful manipulation in research, inducing affect in the laboratory can be problematic $[19,20]$ and may suffer from poor ecological validity.

Experience sampling techniques are needed to capture the dynamic interplay between affect and sexual response while maximizing ecological validity. Additionally, repeated assessments of affect and sexual function allow for the analysis of intraindividual changes (i.e., state-level relations). Much of the prior research on affect and sexual function has used global measures of positive and negative affects. Thus, it remains unclear which specific affect states facilitate these associations. Finally, a number of prior studies examined positive and negative affects separately, rendering it impossible to examine the shared and independent 
effects of positive and negative affects on sexual function. A more nuanced depiction afforded by testing specific affect states and exercising greater statistical control would allow for a clearer understanding of how these constructs are related.

\section{Aims}

The present investigation was a 2 -week prospective study following a sample of young adult women to characterize the manner in which daily experiences of positive (i.e., joviality, self-assurance, and serenity) and negative affects (i.e., fear, sadness, and anger) related to variations in sexual desire, subjective arousal, vaginal lubrication, orgasmic function, and sexual pain. As the sample was nonclinical, our data likely represent normal variations in affect states and sexual function as compared with those found in a psychiatric sample. To reduce potential confounds, we accounted for the influence of age and baseline severity of sexual distress, depression, and anxiety. Additionally, as changes in sexual activity [21] and desire [22] have been associated with the menstrual cycle, the presence of menstruation was also examined as a possible confound. By using repeated assessments, we aimed to capture day-today variations in affect and sexual function and improve ecological validity, while minimizing the effects of recall bias.

Based on findings of past research on affective symptoms and sexual response $[23,24]$, we predicted that positive affect states would be more consistently related to overall female sexual function, particularly sexual desire. This is based on previous findings showing that depression-specific anhedonia symptoms are related to greater sexual difficulties and are consistently related to state and trait desire $[23,24]$. We predicted that negative affect states would be more consistently related to vaginal lubrication, orgasmic function, and sexual pain. A previous study of state relations between affective symptoms and sexual response provided greater support for concurrent, rather than temporal, relations [23]. Thus, we predicted that the relations in this study would also be more concurrent than temporal.

\section{Methods}

\section{Participants}

One hundred and seventy-one women (age: $20.07 \pm 3.32$, range: $18-56$ ) were assessed for a period of 14 days. The sample was mostly Cauca- sian $(81.5 \%)$, although some ethnic diversity was observed (13.3\% African American, 1.2\% Latino or Hispanic, $2.3 \%$ Eastern Asian or Pacific Islander, and 1.8\% "Other"). Approximately 51\% of the sample reported having a significant other. Of these relationships, the average length was 20.71 months $( \pm 18.56)$. Further, $56 \%$ of participants reported having at least one sexual partner at baseline. Of these individuals, 92 women had one sexual partner, two participants had two sexual partners, and one participant had three sexual partners. Participants were recruited from psychology courses at a midwestern university and received course credit for their participation. Inclusion criteria were reliable Internet access and being free of antidepressants for at least the 4 weeks prior to participation. The local institutional review board approved this study. All women provided written informed consent prior to participation.

\section{Procedure}

The study protocol involved a baseline assessment, followed by 14 daily assessments. At baseline, participants reported demographic information and symptoms of sexual distress, depression, and anxiety over the past month, and then received guidance on how to complete the daily, webdelivered questionnaires. Participants were instructed to complete all daily assessments on their home computer upon waking each morning at their habitual wake time. Questionnaires assessed affect and sexual function over the previous 24 hours.

\section{Baseline Measures}

The Center for Epidemiologic Studies Depression Scale (CESD) [25] is a 20-item self-report inventory used to assess symptoms of depression. It was modified to assess these symptoms over the past month. Items were scored on a Likert-type scale $(0-3)$. Scores on the CESD range from 0 to 60 . In the present sample, the CESD achieved high internal consistency $(\alpha=0.90)$.

State-Trait Anxiety Inventory Form X-State (STAIXS) [26] is a 20-item self-report inventory intended to assess levels of anxiety. It was modified to assess these symptoms over the past month. Participants indicated their anxiety symptoms on a Likert-type scale (1-4). Possible scores on the STAIXS range from 20 to 80 . Internal consistency of the STAIXS was high $(\alpha=0.94)$ in the present sample. 
Table 1 Descriptive statistics and zero-order correlations between affect states and sexual function indices

\begin{tabular}{llllllll}
\hline Factor & $\mathrm{M} \pm \mathrm{SD}$, range & $\alpha$ & Serenity & Self-assurance & Fear & Sadness & Hostility \\
\hline Desire & $24.71 \pm 10.45,9-54$ & 0.94 & 0.15 & 0.20 & -0.02 & -0.05 & -0.00 \\
Arousal & $17.19 \pm 2.15,3-18$ & 0.99 & 0.05 & -0.00 & -0.27 & -0.24 & -0.21 \\
Lubrication & $18.57 \pm 2.55,4-20$ & 0.96 & 0.05 & 0.01 & -0.12 & -0.09 & -0.13 \\
Orgasm & $20.46 \pm 3.93,4-24$ & 0.97 & 0.12 & 0.10 & -0.34 & -0.33 & -0.19 \\
Pain & $5.21 \pm 2.56,4-20$ & 0.99 & -0.18 & -0.01 & 0.22 & 0.20 & 0.15 \\
Joviality & $11.51 \pm 4.39,4-20$ & 0.95 & 0.64 & 0.82 & -0.20 & -0.32 & -0.27 \\
Serenity & $5.30 \pm 2.20,2-10$ & 0.92 & - & -0.61 & -0.26 & -0.27 & -0.27 \\
Self-assurance & $12.92 \pm 5.35,5-25$ & 0.92 & - & - & - & -0.24 & -0.21 \\
Fear & $7.63 \pm 2.77,6-30$ & 0.86 & - & - & - & - & 0.55 \\
Sadness & $5.50 \pm 2.53,4-20$ & 0.84 & - & - & - & - & - \\
Hostility & $4.35 \pm 2.06,3-15$ & 0.82 & - & - & - & - \\
\hline
\end{tabular}

Desire, arousal, and orgasm measured using the Profile of Female Sexual Function. Lubrication and pain measured using the Female Sexual Function Index. Joviality, serenity, self-assurance, fear, sadness, and hostility measured using the Positive and Negative Affect Schedule. Significance values are not reported as these correlations are for descriptive purposes only

$\mathrm{M}=$ mean; $\mathrm{SD}=$ standard deviation

The Female Sexual Distress Scale-Revised (FSDS-R) [27] is a 13-item self-report questionnaire used to assess sex-related personal distress in women. In the present study, respondents indicated the extent to which they experienced sexual distress over the past month on a 1-6 Likert-type response scale, with higher scores indicating higher levels of sexual distress. Internal consistency in our sample was adequate $(\alpha=0.74)$.

\section{Main Outcome Measures}

\section{Daily Measures}

The Positive and Negative Affect ScheduleExpanded form (PANAS-X) [28] is a self-report measure that assesses various types of positive and negative affect states. To minimize the time demand of the daily assessments, administration of the PANAS-X was limited to six subscales. Positive affect: joviality (e.g., happy), self-assurance (e.g., proud), and serenity (e.g., calm). Negative affect: fear (e.g., afraid), sadness (i.e., sad), and hostility (i.e., angry). The six scales were chosen as they were hypothesized to be most closely related to sexual functioning, although this hypothesis was largely exploratory. All subscales were modified to assess daily levels of affect. Participants rated these feelings on a five-point Likert-type scale (1-5). See Table 1 for descriptives.

The Profile of Female Sexual Functioning (PFSF) [29,30] is self-report measure of sexual functioning that was modified for daily use in the present study and has been validated for use in nonclinical samples [31]. For the present study, women reported their sexual desire, subjective sexual arousal, and orgasmic function over the previous 24 hours. Scales consist of items on a 1-6
Likert-type response scale. Each scale was scored using raw scores with higher scores indicating better sexual function. Items specific to sexual activity were provided with the response choice of "No Sexual Activity," which was based on MeyerBahlburg and Dolezal's critique of Female Sexual Function Index (FSFI) scoring procedures [32]. See Table 1 for descriptives.

The FSFI [33] is a 19-item self-report measure of sexual functioning that was modified for daily use and has been validated for use in normative samples [31,34,35]. To both avoid construct overlap with the PFSF and to minimize time demand of daily assessments on participants, only the lubrication and pain scales were administered. Both scales consisted of items asking about experiences with sexual function of the previous 24 hours, and scales consisted of items scored on a 1-5 Likert-type response scale. In the present study, each scale was scored using raw scores, with higher scores on the lubrication scale indicating better sexual functioning and higher scores on the pain scale indicating higher levels of vaginal pain. Based on the recommendations of MeyerBahlburg and Dolezal [32], FSFI items were

\footnotetext{
${ }^{1}$ These responses were treated as missing data. For individuals who had less than $25 \%$ missing data in a given scale, proration using participants' mean scores (within that same scale) was used to estimate total factor scores. However, individuals' scale scores were treated as missing if more than $25 \%$ of data in a factor were missing. The rationale was that treating a response of "No Sexual Activity" as zero would artificially bias scores into indicating higher dysfunction, whereas proration allows us to estimate the total scale score based on their other responses in the same scale. However, we decided to only prorate when the response rate was $75 \%$ and above as to minimize the impact of our estimation on the data.
} 
presented with a "No Sexual Activity" response option. ${ }^{1}$ See Table 1 for descriptives.

To measure the presence of menstruation, participants were asked each day "Have you menstruated over the past 24 hours?" and responded either "Yes" (coded as 1) or "No" (coded as 2).

\section{Data Analysis}

The data collected involved repeated assessments. To account for the time-nested structure of the data, analyses were conducted using hierarchical linear modeling (HLM; also known as multilevel modeling). HLM allows for the simultaneous examination of interindividual differences and intraindividual change. As such, this analytic approach can test: the predictive qualities of baseline reports of sexual distress, depression, and anxiety on later sexual function; same-day associations between affect and sexual response; and bidirectional temporal precedence of daily affect and sexual function. Importantly, HLM is robust to missing data, which are common in repeated measures studies [36]. HLM uses full information maximum likelihood (FIML) as a means of estimation. FIML is widely accepted as a superior method of addressing missing data and producing maximally unbiased results $[37,38]$. Rather than imputing missing values, FIML uses only available data to provide estimation [37]. Thus, the HLM models' estimates for indices reflecting sexual activity (i.e., arousal, genital response, pain, orgasmic function) were based on data from days during which sexual activity occurred. That is, estimates were based on data from women who engaged in sexual activity and only on days they engaged in sexual activity. As such, missing data due to not having an available sexual partner (as indicated at baseline) or due to choosing not to engage in sexual activity on a certain day would not affect the relations between affect and sexual response. ${ }^{2}$

\section{Preliminary Analyses}

To examine the impact of baseline characteristics on female sexual function (for individual $i$ at time $t$ ), each outcome variable was predicted by baseline sexual distress, depression, and anxiety (for individual $i$ ), controlling for daily presence of menstruation (for individual $i$ at time $t$ ) and age (for individual $i$ ). These analyses were conducted to

\footnotetext{
${ }^{2}$ Analyses revealed that including baseline partner availability as a covariate in the HLM models did not influence any of the relations between affect and sexual response.
}

determine which variables to use as covariates in the models testing our substantive hypotheses.

Equation 1:

$$
\begin{aligned}
\text { Desire }_{\mathrm{it}}= & \beta_{0 \mathrm{i}}+\beta_{1} \text { Depression }_{\mathrm{i}}+\beta_{2} \text { Anxiety }_{\mathrm{i}} \\
& +\beta_{3} \text { Sexual Distress }_{\mathrm{i}}+\beta_{4} \text { Age }_{\mathrm{i}} \\
& +\beta_{5} \text { Menstruation }_{\mathrm{it}}+\zeta_{0 \mathrm{i}}+\varepsilon_{\mathrm{it}}
\end{aligned}
$$

Equation 1 revealed differences in sexual function outcomes for women with varying baseline severity of depression, anxiety, and sexual distress. Additionally, this model revealed any influence of menstruation as well as age effects on sexual function in the sample. Subsequent analyses included significant predictors as covariates to allow for the testing of relations between daily affect and sexual function independent of higher order symptoms of anxiety and depression, sexual distress, age effects, and impact of daily menstruation.

\section{Substantive Hypotheses}

To examine intraindividual relations between daily affect and female sexual function, we first regressed sexual function onto the same day's affect states while controlling for relevant covariates.

\section{Equation 2:}

$$
\begin{aligned}
\text { Desire }_{\text {it }}= & \beta_{0 \mathrm{i}}+\beta_{1} \text { Joviality }_{\mathrm{it}}+\beta_{2} \text { Self-Assurance }_{\mathrm{it}} \\
& +\beta_{3} \text { Serenity }_{\mathrm{it}}+\beta_{4} \text { Fear }_{\mathrm{it}}+\beta_{5} \text { Sadness }_{\mathrm{it}} \\
& +\beta_{6} \text { Hostility }_{\mathrm{it}}+\beta_{7} \ldots \text { Covariates }_{\mathrm{i}(\mathrm{t})} \\
& +\zeta_{0 \mathrm{i}}+\varepsilon_{\mathrm{it}}
\end{aligned}
$$

Next, to examine temporal relations, we regressed sexual function onto the previous day's affect states while controlling for relevant covariates and the lagged value of the outcome variable. By controlling for the previous day's outcome variable (i.e., at time $\mathrm{t}-1$ ), any significant relations between affect at time $t-1$ and sexual function at time $t$ was independent of the impact of the previous day's sexual functioning.

\section{Equation 3:}

$$
\begin{aligned}
\text { Desire }_{\text {it }}= & \beta_{0 \mathrm{i}}+\beta_{1} \text { Joviality }_{\mathrm{it}-1} \\
& +\beta_{2} \text { Self-Assurance }_{\mathrm{it}-1}+\beta_{3} \text { Serenity }_{\mathrm{it}-1} \\
& +\beta_{4} \text { Fear }_{\mathrm{it}-1}+\beta_{5} \text { Sadness }_{\mathrm{it}-1} \\
& +\beta_{6} \text { Hostility }_{\mathrm{it}-1}+\beta_{7} \text { Desire }_{\mathrm{it}-1} \\
& +\beta_{8} \text {. Covariates }_{\mathrm{i}(\mathrm{t}-1)}+\zeta_{0 \mathrm{i}}+\varepsilon_{\mathrm{it}}
\end{aligned}
$$

In examining sexual function's impact on the following day's affective experience, analyses were 
Table 2 Same-day and temporal relations regressing sexual desire on affect

\begin{tabular}{|c|c|c|c|c|c|c|}
\hline Outcome & Predictor & $\mathrm{B}$ & $z$ & $P$ value & Chi-square & $P$ value \\
\hline \multicolumn{7}{|c|}{ Determining covariates } \\
\hline \multirow[t]{8}{*}{ Desire $_{\text {it }}$} & Level 1 & & & & \multirow[t]{8}{*}{14.31} & \multirow[t]{8}{*}{0.01} \\
\hline & Intercept & 28.07 & 6.65 & $<0.001$ & & \\
\hline & Menstruation $_{\text {it }}$ & 1.64 & 3.03 & $<0.01$ & & \\
\hline & Level 2 & & & & & \\
\hline & Anxiety $_{i}$ & -0.05 & -0.56 & 0.58 & & \\
\hline & Depression $_{i}$ & -0.06 & -0.70 & 0.49 & & \\
\hline & Sexual distress & 0.10 & 1.84 & 0.07 & & \\
\hline & Age & -0.22 & 1.36 & 0.18 & & \\
\hline \multicolumn{7}{|c|}{ Concurrent model } \\
\hline \multirow[t]{9}{*}{ Desire $_{i t}$} & Level 1 & & & & \multirow[t]{9}{*}{184.76} & \multirow[t]{9}{*}{$<0.001$} \\
\hline & Intercept & 12.89 & 7.45 & $<0.001$ & & \\
\hline & Joviality $_{\text {it }}$ & 0.61 & 6.90 & $<0.001$ & & \\
\hline & Self-assurance $_{\text {it }}$ & 0.08 & 0.94 & 0.35 & & \\
\hline & Serenity $_{\text {it }}$ & 0.21 & 1.59 & 0.11 & & \\
\hline & Fear $_{\text {it }}$ & -0.09 & -1.01 & 0.31 & & \\
\hline & Sadness $_{i t}$ & 0.12 & 1.08 & 0.28 & & \\
\hline & Hostility $_{\text {it }}$ & -0.10 & -0.79 & 0.43 & & \\
\hline & Menstruation $_{\text {it }}$ & 1.71 & 3.26 & $<0.001$ & & \\
\hline \multicolumn{7}{|c|}{ Lagged model } \\
\hline \multirow[t]{10}{*}{ Desire $_{\text {it }}$} & Level 1 & & & & \multirow[t]{10}{*}{62.30} & \multirow[t]{10}{*}{$<0.001$} \\
\hline & Intercept & 16.58 & 8.79 & $<0.001$ & & \\
\hline & Joviality $_{i t-1}$ & 0.27 & 2.77 & $<0.01$ & & \\
\hline & Self-assurance $_{i t-1}$ & -0.07 & -0.80 & 0.43 & & \\
\hline & Serenity $_{i t-1}$ & 0.12 & -0.80 & 0.43 & & \\
\hline & Fear $_{\text {it-1 }}$ & 0.19 & 1.84 & 0.07 & & \\
\hline & Sadness $_{\mathrm{it}-1}$ & -0.08 & -0.70 & 0.49 & & \\
\hline & Hostility $_{\text {it-1 }}$ & -0.14 & -1.03 & 0.30 & & \\
\hline & Menstruation $_{\text {it }}$ & 1.72 & 2.90 & $<0.01$ & & \\
\hline & Desire $_{\text {it-1 }}$ & 0.12 & 4.96 & $<0.001$ & & \\
\hline
\end{tabular}

$\mathrm{N}=171$; observations $=2,144$

In multilevel modeling, the chi-square statistic reflects the difference between the tested model and a null model with no predictors. Thus, a significant chi-square is desirable, as it is indicative of a model that accounts for significant variance in the outcome. This is in contrast to the use of chi-square in structural equation modeling, in which significant chi-square statistics are undesirable and reflect a lack of model fit. $B=$ unstandardized beta coefficient. $z$-Scores represent testing the predictor's significance

run in the same manner that the lagged relations in the opposite direction were conducted.

\section{Results}

\section{Preliminary Analyses}

According to the FSDS-R, ${ }^{3} 19.30 \%$ of women in the present study indicated clinically significant levels of sexual distress (19.81 \pm 11.24$)$. Regarding depression and anxiety, $3 \%$ of participants reported clinically significant levels of baseline depression (CESD: $13.37 \pm 9.78$ ) [39], whereas $9 \%$ of participants indicated clinical levels of anxiety (STAIXS: $41.92 \pm 10.98$ ) [40]. See Table 1 for bivariate correlations between affect states and sexual function indices, which we present for

${ }^{3}$ Unlike the original $0-4$ scale, the present study administered the FSDS-R using a 1-6 scale. As such, a clinical cutoff of 27 (calculated to be most parallel to the 11-point cutoff) was used to adjust for the scaling difference. descriptive purposes to orient the reader to the data. Regarding sexual activity, women reported self-stimulation on $8.90 \%$ of days and sexual activity with a partner on $15.46 \%$ of days.

\section{Concurrent Models}

\section{Desire}

We first ran a null model with sexual desire regressed on an intercept, a Level-1 (intraindividual) residual, and a Level-2 (interindividual) residual. Results indicated that approximately 54\% of the total variance in sexual desire was due to intraindividual fluctuations. Thus, the data revealed marked variations in day-to-day levels of desire to justify the examination of time-varying outcomes. Next, we fit a multilevel model estimating sexual desire as predicted by menstruation, age, and baseline anxiety, depression, and sexual distress (see Table 2). Analyses revealed that women experienced greater sexual desire when they were not menstruating $(P<0.01)$. None of the baseline 
Table 3 Same-day and temporal relations regressing subjective arousal on affect

\begin{tabular}{|c|c|c|c|c|c|c|}
\hline Outcome & Predictor & $\mathrm{B}$ & $\mathrm{z}$ & $P$ value & Chi-square & $P$ value \\
\hline \multicolumn{7}{|c|}{ Determining covariates } \\
\hline \multirow[t]{8}{*}{ Arousal $_{\text {it }}$} & Level 1 & & & & 19.53 & $<0.01$ \\
\hline & Intercept & 20.81 & 16.27 & $<0.001$ & & \\
\hline & Menstruation $_{\text {it }}$ & -0.27 & -1.21 & 0.23 & & \\
\hline & Level 2 & & & & & \\
\hline & Anxiety $_{i}$ & -0.01 & 0.30 & 0.76 & & \\
\hline & Depression $_{\mathrm{i}}$ & 0.01 & 0.34 & 0.73 & & \\
\hline & Sexual distress $i$ & -0.06 & -2.79 & $<0.01$ & & \\
\hline & $\mathrm{Age}_{\mathrm{i}}$ & -0.12 & -2.33 & 0.02 & & \\
\hline \multicolumn{7}{|c|}{ Concurrent model } \\
\hline \multirow[t]{11}{*}{ Arousal $_{\text {it }}$} & Level 1 & & & & 68.63 & $<0.001$ \\
\hline & Intercept & 22.42 & 20.98 & $<0.001$ & & \\
\hline & Joviality $_{\text {it }}$ & 0.05 & 1.53 & 0.13 & & \\
\hline & Self-assurance $_{i t}$ & -0.06 & -2.12 & $0.03^{*}$ & & \\
\hline & Serenity $_{\text {it }}$ & -0.04 & -0.78 & 0.44 & & \\
\hline & Fear $_{\text {it }}$ & -0.21 & -5.59 & $<0.001$ & & \\
\hline & Sadnessit & -0.05 & -1.10 & 0.27 & & \\
\hline & Hostility $_{\text {it }}$ & 0.00 & 0.05 & 0.96 & & \\
\hline & Level 2 & & & & & \\
\hline & Sexual distress & -0.04 & -2.50 & 0.01 & & \\
\hline & $\mathrm{Age}_{\mathrm{i}}$ & -0.12 & -2.64 & $<0.01$ & & \\
\hline \multicolumn{7}{|c|}{ Lagged model } \\
\hline \multirow[t]{12}{*}{ Arousal $_{\text {it }}$} & Level 1 & & & & 34.98 & $<0.001$ \\
\hline & Intercept & 15.23 & 7.75 & $<0.001$ & & \\
\hline & Joviality $_{i t-1}$ & -0.05 & -1.08 & 0.28 & & \\
\hline & Self-assurance ${ }_{\text {it-1 }}$ & 0.03 & 0.80 & 0.42 & & \\
\hline & Serenity $_{\mathrm{it}-1}$ & 0.03 & 0.45 & 0.66 & & \\
\hline & Fear $_{\text {it-1 }}$ & -0.02 & -0.31 & 0.76 & & \\
\hline & Sadness $_{\mathrm{it}-1}$ & 0.05 & 0.60 & 0.55 & & \\
\hline & Hostility $_{\mathrm{it}-1}$ & -0.09 & -1.13 & 0.26 & & \\
\hline & Arousal $_{\text {it-1 }}$ & 0.23 & 3.75 & $<0.001$ & & \\
\hline & Level 2 & & & & & \\
\hline & Sexual distress & -0.03 & -2.28 & 0.02 & & \\
\hline & $\mathrm{Age}_{\mathrm{i}}$ & -0.05 & -0.79 & 0.43 & & \\
\hline
\end{tabular}

$n=140 ;$ observations $=571$

*Erroneous significant relation due to poor beta estimation as determined by follow-up analyses

predictors were significant. As such, menstruation was included as a covariate in all subsequent models in which sexual desire was the outcome variable.

We then examined how daily affect related to concurrent sexual desire, controlling for menstruation (see Table 2). Analyses revealed that women experienced greater sexual desire when they were more jovial $(P<0.001)$. No other affect state was independently related to concurrent sexual desire. Menstruation remained a significant predictor such that women experienced greater desire when they were not menstruating $(P<0.001)$.

\section{Subjective Arousal}

The null model indicated that approximately $44 \%$ of the total variance in subjective arousal was due to intraindividual variation. Next, analyses revealed that older women $(P=0.02)$ and women reporting greater sexual distress $(P<0.01)$ experienced lower levels of arousal (see Table 3). We then examined how daily affect predicted subjec- tive arousal, controlling for age and sexual distress. Analyses revealed that women experienced lower levels of arousal when they were more fearful $(P<0.001)$ and self-assured $(P=0.03)$. No other affect state was related to concurrent sexual arousal. Sexual distress $(P=0.01)$ and age $(P<0.01)$ remained significant predictors. Finding that fear and self-assurance were similarly related to sexual arousal was contradictory. Further, the direction of this relation between self-assurance and arousal was not consistent with the descriptive bivariate correlation. Given the large number of predictors and collinearity between affect states, poor estimation of the beta weight was considered. As such, a model regressing subjective arousal only on same-day fear and self-assurance was run to explore this possibility. In this model, higher levels of fear remained related to poorer arousal $(\beta=-0.23, \quad \mathrm{z}=-6.66, P<0.001)$, whereas selfassurance became nonsignificant $(\beta=-0.02$, $\mathrm{z}=-0.12, P=0.22)$. Thus, the earlier finding that 
Table 4 Same-day and temporal relations regressing vaginal lubrication on affect

\begin{tabular}{|c|c|c|c|c|c|c|}
\hline Outcome & Predictor & $\mathrm{B}$ & $z$ & $P$ value & Chi-square & $P$ value \\
\hline \multicolumn{7}{|c|}{ Determining covariates } \\
\hline \multirow[t]{8}{*}{ Lubrication $_{\text {it }}$} & Level 1 & & & & 15.09 & 0.01 \\
\hline & Intercept & 23.20 & 15.13 & $<0.001$ & & \\
\hline & Menstruation $_{\text {it }}$ & -0.32 & -0.89 & 0.37 & & \\
\hline & Level 2 & & & & & \\
\hline & Anxiety & -0.01 & -0.46 & 0.65 & & \\
\hline & Depression $_{i}$ & 0.01 & 0.34 & 0.73 & & \\
\hline & Sexual distress $i$ & -0.03 & -1.64 & 0.10 & & \\
\hline & $\mathrm{Age}_{\mathrm{i}}$ & -0.16 & -2.96 & $<0.01$ & & \\
\hline \multicolumn{7}{|c|}{ Concurrent model } \\
\hline \multirow[t]{10}{*}{ Lubrication $_{\text {it }}$} & Level 1 & & & & 25.36 & $<0.001$ \\
\hline & Intercept & 23.38 & 18.55 & $<0.001$ & & \\
\hline & Joviality $_{\text {it }}$ & 0.04 & 0.95 & 0.34 & & \\
\hline & Self-assurance $_{i t}$ & -0.05 & -1.23 & 0.22 & & \\
\hline & Serenity $_{i t}$ & 0.01 & 0.13 & 0.90 & & \\
\hline & Fear $_{\text {it }}$ & -0.14 & -2.78 & $<0.01$ & & \\
\hline & Sadness $_{\text {it }}$ & -0.00 & -0.05 & 0.96 & & \\
\hline & Hostility $_{i t}$ & -0.04 & -0.62 & 0.53 & & \\
\hline & Level 2 & & & & & \\
\hline & $\mathrm{Age}_{\mathrm{i}}$ & -0.17 & -3.36 & $<0.01$ & & \\
\hline \multicolumn{7}{|c|}{ Lagged model } \\
\hline \multirow[t]{11}{*}{ Lubrication $_{\text {it }}$} & Level 1 & & & & 14.85 & 0.06 \\
\hline & Intercept & 13.89 & 4.71 & $<0.001$ & & \\
\hline & Joviality $_{\text {it-1 }}$ & 0.11 & 1.47 & 0.14 & & \\
\hline & Self-assurance $_{i t-1}$ & -0.06 & -1.06 & 0.29 & & \\
\hline & Serenity $y_{\text {it-1 }}$ & 0.04 & 0.45 & 0.65 & & \\
\hline & Fear $_{\text {it-1 }}$ & -0.04 & -0.42 & 0.68 & & \\
\hline & Sadness $_{\text {it-1 }}$ & 0.12 & 0.83 & 0.41 & & \\
\hline & Hostility $_{\text {it-1 }}$ & 0.08 & 0.67 & 0.50 & & \\
\hline & Lubrication $_{\text {it-1 }}$ & 0.24 & 3.02 & $<0.01$ & & \\
\hline & Level 2 & & & & & \\
\hline & $\mathrm{Age}_{\mathrm{i}}$ & -0.05 & -0.41 & 0.68 & & \\
\hline
\end{tabular}

$n=136 ;$ observations $=476$

self-assurance was related to lower arousal was likely attributable to a type III error, resulting from a bouncing beta.

\section{Vaginal Lubrication}

The null model indicated that intraindividual variation accounted for approximately $48 \%$ of the total variance in vaginal lubrication. Next, analyses revealed that older women reported lower levels of vaginal lubrication $(P<0.01$; see Table 4$)$. We then examined how daily affect predicted lubrication, controlling for age. Analyses revealed that women experienced poorer vaginal lubrication when they were more fearful $(P<0.01)$. No other affect state was significant. Age remained a significant predictor $(P<0.01)$.

\section{Orgasmic Function}

The null model indicated that intraindividual changes accounted for approximately $43 \%$ of the total variance in orgasmic function. Next, analyses revealed that older women $(P=0.02)$ and women with greater sexual distress $(P<0.05)$ reported poorer orgasmic function (see Table 5). We then examined how daily affect predicted orgasmic function, controlling for age and sexual distress. Analyses revealed that women experienced poorer orgasmic function when they were more fearful $(P<0.001)$. No other affect state was significant. Age $(P=0.01)$ and sexual distress $(P=0.02)$ remained significant predictors.

\section{Vaginal Pain}

The null model indicated that intraindividual variation accounted for approximately $46 \%$ of the total variance in vaginal pain. Next, analyses revealed that women with greater baseline sexual distress experienced greater vaginal pain $(P=0.02$; see Table 6$)$. We then examined how daily affect predicted pain, controlling for sexual distress. Analyses revealed that women experienced greater vaginal pain when they were more fearful $(P=0.05)$. No other affect state was significant. Baseline sexual distress remained a significant predictor of vaginal pain $(P=0.02)$. 
Table 5 Same-day and temporal relations regressing orgasmic function on affect

\begin{tabular}{|c|c|c|c|c|c|c|}
\hline Outcome & Predictor & B & z & $P$ value & Chi-square & $P$ value \\
\hline \multicolumn{7}{|c|}{ Determining covariates } \\
\hline \multirow[t]{8}{*}{ Orgasm $_{\text {it }}$} & Level 1 & & & & 17.16 & $<0.01$ \\
\hline & Intercept & 26.57 & 11.41 & $<0.001$ & & \\
\hline & Menstruation $_{\text {it }}$ & -0.06 & -0.14 & 0.89 & & \\
\hline & Level 2 & & & & & \\
\hline & Anxiety $_{i}$ & 0.02 & 0.36 & 0.72 & & \\
\hline & Depression $_{\mathrm{i}}$ & -0.06 & -1.12 & 0.26 & & \\
\hline & Sexual distress $i$ & -0.07 & -1.99 & $<0.05$ & & \\
\hline & $\mathrm{Age}_{\mathrm{i}}$ & -0.20 & -2.36 & 0.02 & & \\
\hline \multicolumn{7}{|c|}{ Concurrent model } \\
\hline \multirow[t]{11}{*}{ Orgasmit $_{\text {it }}$} & Level 1 & & & & 38.13 & $<0.001$ \\
\hline & Intercept & 26.90 & 13.98 & $<0.001$ & & \\
\hline & Joviality $_{\text {it }}$ & -0.00 & -0.00 & 1.00 & & \\
\hline & Self-assurance $_{i t}$ & 0.02 & 0.39 & 0.70 & & \\
\hline & Serenity $_{\text {it }}$ & -0.01 & -0.12 & 0.90 & & \\
\hline & Fear $_{\text {it }}$ & -0.28 & -3.88 & $<0.001$ & & \\
\hline & Sadnessit & -0.09 & -0.89 & 0.37 & & \\
\hline & Hostility $_{\text {it }}$ & 0.09 & 0.89 & 0.37 & & \\
\hline & Level 2 & & & & & \\
\hline & Sexual distress & -0.06 & -2.38 & 0.02 & & \\
\hline & $\mathrm{Age}_{\mathrm{i}}$ & -0.20 & -2.48 & 0.01 & & \\
\hline \multicolumn{7}{|c|}{ Lagged model } \\
\hline \multirow[t]{12}{*}{ Orgasm $_{\text {it }}$} & Level 1 & & & & 40.37 & $<0.001$ \\
\hline & Intercept & 18.03 & 5.25 & $<0.001$ & & \\
\hline & Joviality $_{i t-1}$ & 0.01 & 0.15 & 0.88 & & \\
\hline & Self-assurance ${ }_{\text {it-1 }}$ & 0.08 & 1.10 & 0.27 & & \\
\hline & Serenity $_{\mathrm{it}-1}$ & -0.19 & -1.53 & 0.13 & & \\
\hline & Fear $_{\text {it-1 }}$ & -0.05 & -0.51 & 0.61 & & \\
\hline & Sadness $_{\mathrm{it}-1}$ & -0.16 & -1.16 & 0.25 & & \\
\hline & Hostility $_{\text {it-1 }}$ & 0.12 & 0.83 & 0.40 & & \\
\hline & Orgasm $_{\mathrm{it}-1}$ & 0.34 & 4.90 & $<0.001$ & & \\
\hline & Level 2 & & & & & \\
\hline & Sexual distress & -0.00 & -0.15 & 0.88 & & \\
\hline & $\mathrm{Age}_{\mathrm{i}}$ & -0.20 & -1.46 & 0.14 & & \\
\hline
\end{tabular}

$n=136 ;$ observations $=520$

\section{Temporal Relations}

Regressing Sexual Function on

Previous-Day Affect

In examining temporal relations between affect and female sexual function, we first regressed indices of sexual functioning onto the previous day's affect states while controlling for the previously identified covariates and the outcome variable's lagged value (see Tables 2-6). Overall, fewer temporal effects were found. Specifically, we found that greater joviality predicted higher levels of next-day sexual desire $(P<0.01$; Table 2$)$. To test whether the predictive abilities of joviality on nextday desire were mediated through sexual activity, we estimated the confidence interval (CI) for the indirect effect between joviality and next-day desire, as mediated by sexual activity (a dichotomous variable) using steps outlined by Tofighi and MacKinnon [41]. When regressing desire on sexual activity $(\beta=14.04, \mathrm{z}=29.72, P<0.001)$ and previous-day joviality $(\beta=0.17, \mathrm{z}=3.75$, $P<0.001)$, both predictors were significant. The indirect effect of sexual activity mediating the association between joviality and next-day desire was estimated to be 3.93 (standard error $[\mathrm{SE}]=0.85$ ), and examination of the confidence interval $(95 \%$ $\mathrm{CI}=2.271-5.616)$ indicated that mediation was statistically significant. Other analyses indicated that subjective sexual arousal, vaginal lubrication, orgasmic function, and sexual pain were not predicted by any previous-day affect states.

\section{Regressing Affect on Previous-Day Sexual Function}

Models regressing affect on previous-day sexual functioning were conducted in the same manner as the previously described models (see Table 7). Null models indicated that $40-53 \%$ of the variance in the affect states were due to intraindividual change. Predicting serenity, analyses revealed that greater sexual desire predicted greater next-day serenity while controlling for baseline anxiety. As this relation was not found in the concurrent model, we ran an additional model regressing 
Table 6 Same-day and temporal relations regressing vaginal pain on affect

\begin{tabular}{|c|c|c|c|c|c|c|}
\hline Outcome & Predictor & $\mathrm{B}$ & z & $P$ value & Chi-square & $P$ value \\
\hline \multicolumn{7}{|c|}{ Determining covariates } \\
\hline \multirow[t]{8}{*}{ Pain $_{\text {it }}$} & Level 1 & & & & 12.53 & $<0.001$ \\
\hline & Intercept & 2.30 & 1.46 & 0.15 & & \\
\hline & Menstruation $_{\text {it }}$ & 0.42 & 1.16 & 0.25 & & \\
\hline & Level 2 & & & & & \\
\hline & Anxiety $_{i}$ & 0.05 & 1.72 & 0.09 & & \\
\hline & Depression $_{i}$ & -0.04 & -1.12 & 0.26 & & \\
\hline & Sexual distress & 0.04 & 1.94 & 0.05 & & \\
\hline & $\mathrm{Age}_{\mathrm{i}}$ & 0.02 & 0.42 & 0.67 & & \\
\hline \multicolumn{7}{|c|}{ Concurrent model } \\
\hline \multirow[t]{10}{*}{ Pain $_{\text {it }}$} & Level 1 & & & & 17.59 & 0.01 \\
\hline & Intercept & 3.63 & 4.68 & $<0.001$ & & \\
\hline & Joviality $_{\text {it }}$ & 0.02 & 0.44 & 0.66 & & \\
\hline & Self-assurance $_{\text {it }}$ & 0.02 & 0.48 & 0.63 & & \\
\hline & Serenity $_{\text {it }}$ & -0.10 & -1.49 & 0.14 & & \\
\hline & Fear $_{\text {it }}$ & 0.11 & 1.96 & 0.05 & & \\
\hline & Sadnessit & 0.05 & 0.74 & 0.46 & & \\
\hline & Hostility $_{\text {it }}$ & -0.04 & -0.61 & 0.54 & & \\
\hline & Level 2 & & & & & \\
\hline & Sexual distress ${ }_{i}$ & 0.04 & 2.26 & 0.02 & & \\
\hline \multicolumn{7}{|c|}{ Lagged model } \\
\hline \multirow[t]{11}{*}{ Pain $_{\text {it }}$} & Level 1 & & & & 83.07 & $<0.001$ \\
\hline & Intercept & 2.38 & 2.15 & 0.03 & & \\
\hline & Joviality $_{\text {it-1 }}$ & -0.04 & -0.60 & 0.55 & & \\
\hline & Self-assurance $_{\mathrm{it}-1}$ & 0.03 & 0.62 & 0.54 & & \\
\hline & Serenity $_{\mathrm{it}-1}$ & -0.11 & -1.23 & 0.22 & & \\
\hline & Fear $_{\text {it-1 }}$ & -0.08 & -0.91 & 0.36 & & \\
\hline & Sadness $_{\mathrm{it}-1}$ & 0.15 & 1.00 & 0.32 & & \\
\hline & Hostility $_{\mathrm{it}-1}$ & -0.04 & -0.34 & 0.73 & & \\
\hline & Pain $_{\text {it-1 }}$ & 0.64 & 8.16 & $<0.001$ & & \\
\hline & Level 2 & & & & & \\
\hline & Sexual distress ${ }_{i}$ & 0.01 & 0.42 & 0.67 & & \\
\hline
\end{tabular}

serenity on only the previous day's desire $(\beta=0.02$, $\mathrm{z}=3.99, P<0.001$, which was significant and thus suggested this finding was not likely to be erroneous. To test whether the predictive abilities of sexual desire on next-day serenity were mediated through sexual activity, we estimated the confidence interval for the indirect effect between desire and serenity, mediated by sexual activity. When regressing serenity onto sexual activity $(\beta=0.02, \mathrm{z}=3.99, P<0.001)$ and previous-day desire $(\beta=0.34, \mathrm{z}=3.21, P<0.01)$, both predictors were significant. Further, the indirect effect estimate was $0.007(\mathrm{SE}=0.003)$, and examination of the confidence interval ( $95 \% \mathrm{CI}=0.002-0.012$ ) indicated that mediation was statistically significant. This finding suggested that sexual desire does predict next-day serenity but that this relation was partially mediated by sexual activity, though the size of the indirect effect is modest.

The next significant relation revealing sexual function predicting next-day affect indicated that greater desire was related to greater next-day fear. This finding was inconsistent with the descriptive bivariate correlation and the covariance model.
Thus, concern for a type III error was considered. We then regressed fear only on the previous day's sexual desire $(\beta=-0.01, \mathrm{z}=-1.34, \quad P=0.18)$, which revealed that desire did not predict next-day fear. As such, the finding was interpreted as a type III error due to poor beta estimation. We also found that better orgasmic function predicted less next-day sadness, whereas better lubrication predicted greater next-day sadness. However, as neither of these relations was found in the covariance model, we wanted to rule out erroneous significant findings. Thus, we regressed sadness on the previous day's vaginal lubrication and orgasmic function without any other predictors in separate models. The first model indicated that lubrication $(\beta=-0.04, \mathrm{z}=-0.99, P=0.32)$ did not predict next-day sadness. As such, this finding was identified as a multicollinearity artifact. In contrast, regressing sadness on the previous day's orgasmic function showed that better orgasmic functioning predicted low levels of sadness the following day $(P=0.03)$. We then re-ran the model regressing sadness on previous-day orgasmic function and the lagged outcome value and found that 
Table 7 Temporal relations regressing affect on previous-day sexual function

\begin{tabular}{|c|c|c|c|c|c|c|}
\hline Outcome & Predictor & $\mathrm{B}$ & z & $P$ value & Chi-square & $P$ value \\
\hline \multirow[t]{8}{*}{ Joviality $_{\text {it }}$} & Level 1 & & & & 68.17 & $<0.001$ \\
\hline & Intercept & 19.48 & 11.13 & $<0.001$ & & \\
\hline & Menstruation $_{\text {it }}$ & -0.08 & -0.43 & 0.67 & & \\
\hline & Level 2 & & & & & \\
\hline & Anxiety $_{i}$ & -0.09 & -2.65 & 0.09 & & \\
\hline & Depression $_{i}$ & -0.12 & -3.12 & $<0.01$ & & \\
\hline & Sexual distress $s_{i}$ & 0.02 & 0.96 & 0.34 & & \\
\hline & $\mathrm{Age}_{\mathrm{i}}$ & -0.03 & -0.46 & 0.64 & & \\
\hline \multirow[t]{11}{*}{ Joviality $_{\text {it }}$} & Level 1 & & & & 120.96 & $<0.001$ \\
\hline & Intercept & 12.36 & 5.22 & $<0.001$ & & \\
\hline & Desire $_{i t-1}$ & 0.03 & 1.08 & 0.28 & & \\
\hline & Arousal $_{\text {it-1 }}$ & -0.20 & -1.60 & 0.11 & & \\
\hline & Lubrication $_{\mathrm{it}-1}$ & 0.02 & 0.16 & 0.87 & & \\
\hline & Orgasm $_{\mathrm{it}-1}$ & 0.03 & 0.48 & 0.63 & & \\
\hline & Pain $_{\text {it-1 }}$ & -0.12 & -1.34 & 0.18 & & \\
\hline & Joviality $_{i t-1}$ & 0.40 & 7.32 & $<0.001$ & & \\
\hline & Level 2 & & & & & \\
\hline & Anxiety $_{i}$ & -0.08 & -2.21 & 0.03 & & \\
\hline & Depression $_{i}$ & -0.01 & -0.14 & 0.89 & & \\
\hline \multirow[t]{7}{*}{ Self-assurance $_{\text {it }}$} & Level 1 & & & & 50.86 & $<0.001$ \\
\hline & Menstruation $_{\text {it }}$ & -0.18 & -0.86 & 0.39 & & \\
\hline & Level 2 & & & & & \\
\hline & Anxiety & -0.13 & -2.81 & $<0.01$ & & \\
\hline & Depression $_{i}$ & -0.10 & -1.96 & 0.05 & & \\
\hline & Sexual distress $s_{i}$ & 0.01 & 0.44 & 0.66 & & \\
\hline & $\mathrm{Age}_{\mathrm{i}}$ & 0.03 & 0.29 & 0.77 & & \\
\hline \multirow[t]{11}{*}{ Self-assurance $_{\text {it }}$} & Level 1 & & & & 251.35 & $<0.001$ \\
\hline & Intercept & 12.33 & 4.79 & $<0.001$ & & \\
\hline & Desire $_{i t-1}$ & 0.01 & 0.51 & 0.61 & & \\
\hline & Arousal $_{\mathrm{it}-1}$ & -0.11 & -0.82 & 0.41 & & \\
\hline & Lubrication $_{\text {it-1 }}$ & -0.10 & -0.96 & 0.34 & & \\
\hline & Orgasm $_{\mathrm{it}-1}$ & 0.05 & 0.89 & 0.38 & & \\
\hline & Pain $_{\text {it-1 }}$ & -0.16 & -1.59 & 0.11 & & \\
\hline & Self-assurance $\mathrm{it}_{\mathrm{it}-1}$ & 0.55 & 11.59 & $<0.001$ & & \\
\hline & Level 2 & & & & & \\
\hline & Anxiety & -0.09 & -2.42 & 0.02 & & \\
\hline & Depression $_{i}$ & -0.01 & -0.13 & 0.90 & & \\
\hline \multirow[t]{8}{*}{ Serenity $y_{i t}$} & Level 1 & & & & 76.18 & $<0.001$ \\
\hline & Intercept & 8.46 & 9.89 & $<0.001$ & & \\
\hline & Menstruation $_{\text {it }}$ & 0.01 & 0.11 & 0.91 & & \\
\hline & Level 2 & & & & & \\
\hline & Anxiety $_{i}$ & -0.07 & -4.31 & $<0.001$ & & \\
\hline & Depression $_{i}$ & -0.02 & -1.13 & 0.26 & & \\
\hline & Sexual distress $i_{i}$ & -0.00 & -0.27 & 0.79 & & \\
\hline & $\mathrm{Age}_{\mathrm{i}}$ & 0.03 & 0.79 & 0.43 & & \\
\hline \multirow[t]{10}{*}{ Serenity $_{\text {it }}$} & Level 1 & & & & 129.36 & $<0.001$ \\
\hline & Intercept & 7.41 & 6.14 & $<0.001$ & & \\
\hline & Desire $_{\mathrm{it}-1}$ & 0.03 & 2.20 & 0.03 & & \\
\hline & Arousal $_{\mathrm{it}-1}$ & -0.10 & -1.58 & 0.11 & & \\
\hline & Lubrication $_{\text {it-1 }}$ & 0.01 & 0.21 & 0.83 & & \\
\hline & Orgasm $_{\mathrm{it}-1}$ & -0.03 & -1.01 & 0.32 & & \\
\hline & Pain $_{\text {it-1 }}$ & -0.05 & -1.10 & 0.27 & & \\
\hline & Self-assurance $\mathrm{it}_{\mathrm{t}-1}$ & 0.34 & 6.78 & $<0.001$ & & \\
\hline & Level 2 & & & & & \\
\hline & Anxiety & -0.06 & -4.95 & $<0.001$ & & \\
\hline \multirow[t]{8}{*}{ Fear $_{\text {it }}$} & Level 1 & & & & 84.66 & $<0.001$ \\
\hline & Intercept & 3.48 & 3.46 & $<0.01$ & & \\
\hline & Menstruation $_{\text {it }}$ & -0.14 & -1.11 & 0.27 & & \\
\hline & Level 2 & & & & & \\
\hline & Anxiety $_{i}$ & 0.05 & 2.67 & $<0.01$ & & \\
\hline & Depression $_{i}$ & 0.07 & 3.50 & $<0.001$ & & \\
\hline & Sexual distress $s_{i}$ & -0.01 & -0.45 & 0.65 & & \\
\hline & $\mathrm{Age}_{\mathrm{i}}$ & -0.00 & -0.02 & 0.98 & & \\
\hline
\end{tabular}


Table 7 Continued

\begin{tabular}{|c|c|c|c|c|c|c|}
\hline Outcome & Predictor & $\mathrm{B}$ & z & $P$ value & Chi-square & $P$ value \\
\hline \multirow[t]{11}{*}{ Fear $_{\text {it }}$} & Level 1 & & & & 93.95 & $<0.001$ \\
\hline & Intercept & 2.01 & 1.61 & 0.11 & & \\
\hline & Desire $_{i t-1}$ & 0.03 & 2.09 & $0.04^{*}$ & & \\
\hline & Arousal $_{\mathrm{it}-1}$ & 0.06 & 0.89 & 0.38 & & \\
\hline & Lubrication $_{\mathrm{it}-1}$ & 0.24 & 0.46 & 0.65 & & \\
\hline & Orgasm $_{\mathrm{it}-1}$ & -0.05 & -1.70 & 0.09 & & \\
\hline & Pain $_{\text {it-1 }}$ & -0.08 & -1.55 & 0.12 & & \\
\hline & Fear $_{\text {it-1 }}$ & 0.27 & 5.58 & $<0.001$ & & \\
\hline & Level 2 & & & & & \\
\hline & Anxiety & 0.01 & 0.69 & 0.49 & & \\
\hline & Depression $_{i}$ & 0.05 & 2.13 & 0.03 & & \\
\hline \multirow[t]{8}{*}{ Sadness $_{i t}$} & Level 1 & & & & 123.63 & $<0.001$ \\
\hline & Intercept & 1.09 & 1.26 & 0.21 & & \\
\hline & Menstruation $_{\text {it }}$ & 0.06 & 0.53 & 0.60 & & \\
\hline & Level 2 & & & & & \\
\hline & Anxiety & 0.02 & 1.12 & 0.26 & & \\
\hline & Depression $_{\mathrm{i}}$ & 0.11 & 6.29 & $<0.001$ & & \\
\hline & Sexual distress ${ }_{i}$ & -0.01 & -0.87 & 0.39 & & \\
\hline & $\mathrm{Age}_{\mathrm{i}}$ & -0.00 & -0.05 & 0.96 & & \\
\hline \multirow[t]{10}{*}{ Sadness $_{\text {it }}$} & Level 1 & & & & 127.19 & $<0.001$ \\
\hline & Intercept & 2.38 & 2.37 & 0.02 & & \\
\hline & Desire $_{i t-1}$ & 0.00 & 0.01 & 0.99 & & \\
\hline & Arousal $_{\mathrm{it}-1}$ & -0.08 & -1.25 & 0.21 & & \\
\hline & Lubrication $_{\text {it-1 }}$ & 0.10 & 2.18 & $0.03^{*}$ & & \\
\hline & Orgasm $_{\mathrm{it}-1}$ & -0.06 & -2.39 & 0.02 & & \\
\hline & Pain $_{\text {it-1 }}$ & -0.01 & -0.21 & 0.83 & & \\
\hline & Sadnessit-1 $_{\text {S }}$ & 0.28 & 6.54 & $<0.001$ & & \\
\hline & Level 2 & & & & & \\
\hline & Depression $_{i}$ & 0.06 & 4.62 & $<0.001$ & & \\
\hline \multirow[t]{8}{*}{ Hostility $_{\text {it }}$} & Level 1 & & & & 56.42 & $<0.001$ \\
\hline & Intercept & 2.29 & 2.96 & $<0.01$ & & \\
\hline & Menstruation $_{\text {it }}$ & -0.22 & -2.12 & 0.03 & & \\
\hline & Level 2 & & & & & \\
\hline & Anxiety & 0.04 & 2.75 & $<0.01$ & & \\
\hline & Depression $_{i}$ & 0.02 & 1.26 & 0.21 & & \\
\hline & Sexual distress ${ }_{i}$ & 0.02 & 1.47 & 0.14 & & \\
\hline & $\mathrm{Age}_{\mathrm{i}}$ & -0.01 & -0.31 & 0.76 & & \\
\hline \multirow[t]{11}{*}{ Hostility $_{i t}$} & Level 1 & & & & 76.96 & $<0.001$ \\
\hline & Intercept & 1.99 & 1.56 & 0.12 & & \\
\hline & Desire $_{\mathrm{it}-1}$ & 0.01 & 0.60 & 0.55 & & \\
\hline & Arousal $_{\mathrm{it}-1}$ & -0.01 & -0.23 & 0.82 & & \\
\hline & Lubrication $_{\text {it-1 }}$ & 0.07 & 1.44 & 0.15 & & \\
\hline & Orgasm $_{\mathrm{it}-1}$ & -0.05 & -1.70 & 0.09 & & \\
\hline & Pain $_{\text {it-1 }}$ & -0.01 & -0.25 & 0.81 & & \\
\hline & Hostility $_{\text {it-1 }}$ & 0.27 & 5.64 & $<0.001$ & & \\
\hline & Menstruation $_{\text {it }}$ & -0.41 & -1.26 & 0.21 & & \\
\hline & Level 2 & & & & & \\
\hline & Anxiety & -0.01 & -0.23 & 0.82 & & \\
\hline
\end{tabular}

*Erroneous significant relation due to poor beta estimation as determined by follow-up analyses $\mathrm{n}=125$; observations $=404-407$

better orgasmic function predicted a decrease in sadness the following day $(\beta=-0.06, z=-2.25$, $P=0.03)$.

\section{Menstruation, Affect, and Sexual Function}

In addition to the study's primary aims, relations between daily menstruation, affect, and sexual function and activity were found. Women reported lower desire when menstruating $(P<0.001$; see Table 2 concurrent model), whereas menstruation was not related to arousal, lubrication, orgasmic function, or sexual pain (see Tables 2-6). However, multilevel logistical regression revealed that women were more than twice as likely to abstain from sexual activity when they were menstruating (odds ratio $=2.68, \beta=0.98, \mathrm{z}=3.91, P<0.001$ ). Though, when examining menstruation's influence on arousal, lubrication, orgasmic function, and pain, we found that the average number of observations per participant for each analysis 
ranged from 3.4 to 3.9 (i.e., indication that although less likely, women did engage in sexual activity on days they menstruated), it is possible that the low number of observations per participant resulted in a lack of power to detect any relations between menstruation and other indices of sexual function. Regarding menstruation and daily affect, women were more hostile when they were menstruating $(P=0.03$; see Table 7 covariate model). No other relation between menstruation and daily affect was observed.

\section{Discussion}

The present study used daily assessments over a 2 -week period to examine changes in affect and corresponding variation in female sexual function. Evidence supported specificity between affect states and indices of sexual function. Specifically, we found joviality (i.e., happiness, enthusiasm) and-to a lesser extent—serenity (i.e., feeling calm and relaxed) to be uniquely related to sexual desire, whereas fear was independently related to same-day subjective arousal, lubrication, orgasmic function, and vaginal pain. Finally, we found that better orgasmic function predicted decreased next-day sadness. Overall, these relations were more concurrent than temporal and were robust to the influences of daily menstruation, age effects, and baseline sexual distress and affective symptoms. Demonstrating that daily affect and sexual function fluctuate together on a day-to-day basis underlines the inextricability of emotional and sexual health.

A greater number of concurrent relations between daily affect and sexual function were found than temporal relations in either direction. Regarding positive affect, when women were happier, they experienced greater sexual desire. No other concurrent relations were found between positive affect and female sexual function indices. Regarding negative affect, women experienced poorer subjective arousal, vaginal lubrication, and orgasmic function, as well as greater sexual pain, on days they were more fearful.

Although relations between affect and sexual function were more concurrent than temporal, a small number of temporal relations were observed. In the direction of affect predicting next-day sexual function, we found that when women were happier, they experienced greater sexual desire the following day. Additional analysis indicated that this relation was partially mediated by sexual activity such that when women were happy, they were more likely to engage in sexual activity the next day, which was related to greater feelings of sexual desire. No other affect states predicted next-day sexual function in the present study.

In the opposite direction, we found that when women reported greater sexual desire, they experienced greater calmness the next day. Upon further examination, results indicated that desire's impact on later serenity was partially mediated by sexual activity. That is, not only did greater desire directly lead to higher levels of calmness the following day but when women felt greater desire, they engaged in sexual activity the following day, which was associated with greater calmness and relaxation. Additionally, results indicated that better orgasmic functioning corresponded to decreases in sadness the next day. It is unclear, however, if the decreases in sadness were due to better orgasmic functioning or if the relation was driven primarily by the actual acbievement of orgasm during sexual activity.

Daily affect's association with female sexual function may shed light not only on the daily transaction between affect and sexual function but also on the presence of sexual difficulties in the context of depressed or anxious mood. As depression and anxiety disorders are, at least in part, the product of chronically and severely dysregulated affect, intraindividual (i.e., state-level) relations between affect and sexual function may offer insight into the development of comorbid depression, anxiety, and female sexual dysfunction.

High negative affect (i.e., fear, sadness) has been identified as being similarly related to both depression and anxiety $[42,43]$. In other words, sadness and fear, in and of themselves, do not reliably differentiate between the two disorders. As such, finding that fear was consistently and robustly related to same-day arousal, lubrication, orgasmic function, and sexual pain may explain why both depression and anxiety disorders have been similarly linked to these indices of sexual function [1]. To illustrate, these findings indicate that the extent to which women experience fear corresponds to their capacity for arousal, ability to achieve orgasm, and degree of sexual pain. Consistent with a stress-diathesis model, symptoms of depression and anxiety in response to a major life event may manifest as chronic fear and worry, physical tension, and self-isolation because of lack of motivation and unhappiness. Along with these cognitive, emotional, and somatic changes, diminished subjective arousal and difficulty with genital response and orgasm achievement are likely to be 
experienced. As increased severity and chronicity of fear and general distress (i.e., shared symptoms of depression and anxiety) [42] correspond to simultaneous decreases in levels of arousal and orgasmic function, as well as greater pain, our findings describe how these changes in normative affect and sexual response can coevolve into more clinical states. In other words, it may not be that negative affect or fear leads to co-occurring sexual problems but that both are the result of the same underlying processes. Notably, this interpretation is consistent with recent conceptualizations offered in the literature proposing that depression, anxiety, and sexual dysfunction comprise related forms of internal psychopathology $[1,2,44]$.

However, it is difficult to overlook that it was fear, but not sadness, that was uniquely related to arousal indices, orgasmic function, and sexual pain. Notably, activation of the autonomic nervous system plays an important role in anxiety $[45,46]$, sexual arousal, and genital blood flow $[47,48]$, and some research has shown that anxietyspecific symptoms (i.e., physiological arousal, e.g., increased heart rate, muscle tension) are related to poorer lubrication and orgasmic function, and greater vaginal pain [24]. Given the commonality of somatic arousal to these aspects of mental and sexual health, dysregulation of these systems may constitute a shared risk or mediating factor between fear or anxiety and these sexual difficulties. Thus, one potential underlying mechanism that may drive the relation between fear and sexual dysfunction may be autonomic dysregulation. That is, as an individual experiences greater physiological hyperarousal, she may experience increases in both fear and sexual difficulties, consistent with a coevolution hypothesis. It may behoove future investigators to explore this possibility.

Additionally, as anhedonia is an affective symptom unique to depression [42], our finding that lower levels of happiness, enthusiasm, and cheerfulness are related to same-day diminished desire indicates that diminished desire is uniquely related to depression-specific symptoms. Additionally, results showing that lower joviality predicted next-day decreases in desire may be suggestive of depression-specific affect symptoms conferring a vulnerability to diminished libido. These findings are consistent with past research examining the trait and state relations of anhedonia and female sexual desire $[23,24]$. Similar to the previously provided example, our findings suggest that depression and hypoactive desire symptoms may coevolve. That is, a psychologically healthy individual who is exposed to a stressor may experience simultaneous reductions in happiness, enthusiasm, and interest in sex. If these simultaneous changes develop into clinical states, this coevolution may partially account for the high comorbidity between depression and low levels of sexual desire. It would serve future studies well to explore the mechanisms facilitating the relation between joviality (or lack thereof in anhedonia) and sexual desire. For instance, a number of studies have shown dopamine activity to be related to a lack of pleasure and depression (see Treadway and Zald [49] for review) and the neurobiology of sexual desire [47]. Taken together, it is possible that depressed affect and hypoactive desire share similar pathophysiology.

The findings of the present study should be interpreted in the context of certain limitations. Notably, the present study's sample consisted of young women who were less likely to be encumbered by medical illnesses or severe mental health disorders as compared with older or clinical samples. Even so, women in the present study were not screened for other psychological or medical issues or medications that could potentially impact these findings. As such, future studies are necessary to determine whether these results generalize to older women or individuals with clinical affective or sexual disorders. Furthermore, examination of these relations is needed in men, as the specificity between affect and sexual function in men may not mirror the relations found in women. Regarding our measure of affect, the present study used six affect scales in examining positive and negative affects, which do not fully capture all dimensions of positive and negative affects. Additionally, the degree of balance between positive and negative affects has been shown to be important to sexual response [50]. Thus, future investigations may consider examining how variations in the degree of balance between positive and negative affects correspond to changes in sexual function.

An additional limitation regards statistical power. Although the study benefited from a large sample and number of observations, two study characteristics threatened power to detect effects. First, our sample was relatively healthy in regard to emotional and sexual health. Thus, range restriction of target variables may have hindered the ability to detect relations. Indeed, daily negative affect and sexual function (excluding desire) indices' means and standard deviations reveal a floor and ceiling effects (see Table 1). Secondly, given the large number of correlated predictors in the HLM models, collinearity and overdeter- 
mination were threats to power and beta estimation. Further, specific to the temporal models, lagged outcome values were entered as covariates. Outcome variables and their lagged values are highly related and are likely to be related to the same stochastic parts. Although we believe that controlling for these covariates was important for ruling out potential confounds and that entering each of the six affect states in a single model (rather than in individual models) to decrease the risk for type I error was important, these statistical decisions likely increased the risk of type II, and even type III, errors.

Despite these limitations, the present study also offers a number of clinical implications for individuals presenting with sexual problems thought to be largely psychogenic or in the context of depression or anxiety. Namely, the results are consistent with prior investigations indicating that women presenting with a dysfunctional balance of positive and negative affects (i.e., low positive affect relative to high positive-negative affect) are vulnerable to sexual dysfunction and distress [50,51]. As such, women with these low positive and high negative affect profiles may experience poorer treatment response to pharmacologic and psychological interventions as compared to women with more evenly balanced or positive affect profiles. However, this knowledge may help inform treatment planning. For women presenting with a primary complaint of diminished sexual desire, increasing positive affect may be therapeutic and enhance capacity for sexual desire. Conversely, it may be that placing greater emphasis on reducing fear may better target primary complaints regarding arousal, orgasm, or pain difficulties that present with psychological perpetuating factors. As fear was concurrently related to these aspects of female sexual function, then techniques to decrease both affective and somatic tension, such as progressive muscle relaxation or mindfulness exercises, may be useful skills to teach women with these complaints. Recent research has shown muscle relaxation and mindfulness exercises to benefit women with sexual arousal and pain difficulties [52-54]. However, these techniques have not received much attention in the literature for the treatment of sexual dysfunction and may present as a rich and largely untapped area to explore. Importantly, as affective experiences are complex and interrelated, increasing positive affect and teaching mindfulness and relaxation techniques are likely to benefit overall female sexual response.

\section{Conclusions}

Changes in female sexual response are closely tied to day-to-day fluctuations in happiness, enthusiasm, calmness, and fear. Importantly, these daily changes in sexual function and affect predominantly occur simultaneously, suggesting that they may, in part, represent manifestations of the same facilitating mechanisms. Future directions in research on normative and pathological affect and sexual response should focus on identifying underlying neurobiological, physiological, and cognitive processes related to changes in both affective experiences and female sexual functioning.

Corresponding Author: David A. Kalmbach, $\mathrm{PhD}$, Department of Psychiatry, Sleep and Chronophysiology Laboratory, University of Michigan, Rachel Upjohn Building, 4250 Plymouth Road, Ann Arbor, MI 48105, USA. Tel: 330 204-6942; Fax: 734 845-3233; E-mail: dkalmbac@gmail.com

Conflict of Interest: Mr. Kalmbach reports no conflict of interest. Dr. Pillai reports no conflict of interest.

\section{Statement of Authorship}

Category I

(a) Conception and Design

David A. Kalmbach

(b) Acquisition of Data

David A. Kalmbach

(c) Analysis and Interpretation of Data

David A. Kalmbach; Vivek Pillai

\section{Category 2}

(a) Drafting the Article

David A. Kalmbach

(b) Revising It for Intellectual Content

David A. Kalmbach; Vivek Pillai

\section{Category 3}

(a) Final Approval of the Completed Article

David A. Kalmbach; Vivek Pillai

\section{References}

1 Laurent SM, Simons AD. Sexual dysfunction in depression and anxiety: Conceptualizing sexual dysfunction as part of an internalizing dimension. Clin Psychol Rev 2009;29:573-85.

2 Oliveira C, Nobre PJ. The role of trait-affect, depression, and anxiety in women with sexual dysfunction: A pilot study. J Sex Marital Ther 2013;39:436-52.

3 Peixoto M, Nobre PJ. Female sexual desire and trait-affect: The mediator role of depressed mood. 21st World Congress for Sexual Health. Porto Alegre, Brazil, September 21-24, 2013. 
4 Hayes RD, Dennerstein L, Bennett CM, Sidat M, Gurrin LC, Fairley CK. Risk factors of female sexual dysfunction in the general population: Exploring factors associated with low sexual function and distress. J Sex Med 2008;5:1681-93.

5 Atlantis E, Sullivan T. Bidirectional association between depression and sexual dysfunction: A systematic review and meta-analysis. J Sex Med 2012;9:1497-507.

6 Watson D, Clark LA, Tellegen A. Development and validation of brief measures of positive and negative affect: The PANAS scales. J Pers Soc Psychol 1988;54:1063-70.

7 Tellegen A, Watson D, Clark LA. On the dimensional and hierarchical structure of affect. Psychol Sci 1999;10:297-303.

8 Clark LA, Watson D, Leeka J. Diurnal variation in the positive affects. Motiv Emotion 1989;13:205-34.

9 Watson D, Tellegen A. Toward a consensual structure of mood. Psychol Bull 1985;98:219-35.

10 Watson D, et al. Testing a tripartite model: II. Exploring the symptom structure of anxiety and depression in student, adult, and patient samples. J Abnorm Psychol 1995;104:15-25.

11 Kalmbach DA, Pillai V, Roth T, Drake CL. The interplay between daily affect and sleep: A two-week study of young women. J Sleep Res in press. doi: 10.1111/jsr.12190.

12 Pressman SD, Cohen S. Does positive affect influence health? Psychol Bull 2005;131:925-71.

13 Steptoe A, Wardle J, Marmot M. Positive affect and healthrelated neuroendocrine, cardiovascular, and inflammatory processes. Proc Natl Acad Sci U S A 2005;102:6508-12.

14 Peterson ZD, Janssen E. Ambivalent affect and sexual response: The impact of co-occurring positive and negative emotions on subjective and physiological sexual responses to erotic stimuli. Arch Sex Behav 2007;36:793-807.

15 Laan E, Everaerd W, van Bellen G, Hanewald G. Women's sexual and emotional responses to male- and female-produced erotica. Arch Sex Behav 1994;23:153-69.

16 Heiman JR. Female sexual response patterns: Interactions of physiological, affective, and contextual cues. Arch Gen Psychiatry 1980;37:1311-6.

17 Laan E, Everaerd W, van Berlo R, Rijs L. Mood and sexual arousal in women. Behav Res Ther 1995;33:441-3.

18 Laan E, Everaerd W. Determinants of female sexual arousal: Psychophysiological theory and data. Annu Rev Sex Res 1995;6:32-76.

19 Westermann R, Spies K, Stahl G, Hesse FW. Relative effectiveness and validity of mood induction procedures: A metaanalysis. Eur J Soc Psychol 1996;26:557-80.

20 Västfjäll D. Emotion induction through music: A review of the musical mood induction procedure. Music Sci 2002;5(1 suppl): 173-211.

21 Bancroft J, Sanders D, Davidson D, Warner P. Mood, sexuality, hormones, and the menstrual cycle. III. Sexuality and the role of androgens. Psychosom Med 1983;45:509-16.

22 Regan PC. Rhythms of desire: The association between menstrual cycle phases and female sexual desire. Can J Hum Sex 1996;5:145-56.

23 Kalmbach DA, Pillai V, Kingsberg SA, Ciesla JA. The transaction between depression and anxiety symptoms and sexual functioning: A prospective study of premenopausal, healthy women. Arch Sex Behav in press.

24 Kalmbach DA, Ciesla JA, Janata JW, Kingsberg SA. Specificity of anhedonic depression and anxious arousal with sexual problems among sexually healthy young adults. J Sex Med 2012;9:505-13.

25 Radloff LS. The CES-D scale a self-report depression scale for research in the general population. Appl Psychol Meas 1977;1:385-401.

26 Spielberger CD, Gorssuch RL, Lushene PR, Vagg PR, Jacobs GA. Manual for the state-trait anxiety inventory. Palo Alto, CA: Consulting Psychologists Press, Inc; 1983.
27 DeRogatis L, Clayton A, Lewis-D'Agostino D, Wunderlich G, $\mathrm{Fu}$ Y. Validation of the female sexual distress scale-revised for assessing distress in women with hypoactive sexual desire disorder. J Sex Med 2008;5:357-64.

28 Watson D, Clark LA. The PANAS-X: Manual for the positive and negative affect schedule-expanded form. Iowa City: University of Iowa; 1999.

29 McHorney CA, Rust J, Golombok S, Davis S, Bouchard C, Brown C, Basson R, Sarti CD, Kuznicki J, Rodenberg C, Derogatis L. Profile of Female Sexual Function: A patientbased, international, psychometric instrument for the assessment of hypoactive sexual desire in oophorectomized women. Menopause 2004;11:474-83.

30 DeRogatis L, Rust J, Golombok S, Bouchard C, Nachtigall L, Rodenberg C, Kuznicki J, McHorney CA. Validation of the profile of female sexual function (PFSF) in surgically and naturally menopausal women. J Sex Marital Ther 2004;30: 25-36.

31 Kalmbach DA, Ciesla JA, Janata JW, Kingsberg SA. The validation of the female sexual function index, male sexual function index, and profile of female sexual function for use in healthy, young adults. Arch Sex Behav in press. DOI: 10.1007/ s10508-014-0334-y.

32 Meyer-Bahlburg HF, Dolezal C. The Female Sexual Function Index: A methodological critique and suggestions for improvement. J Sex Marital Ther 2007;33:217-24.

33 Rosen RC, Brown C, Heiman J, Leiblum S, Meston C, Shabsigh R, Ferguson D, D'Agostino R Jr. The female sexual function index (FSFI): A multidimensional self-report instrument for the assessment of female sexual function. J Sex Marital Ther 2000;26:191-208.

34 Carvalho J, Vieira AL, Nobre PJ. Latent structures of female sexual functioning. Arch Sex Behav 2012;41:907-17.

35 Opperman EA, Benson LE, Milhausen RR. Confirmatory factor analysis of the female sexual function index. J Sex Res 2013;50:29-36.

36 Singer JD, Willett JB. Applied longitudinal data analysis: Modelling change and event occurrence. New York: Oxford University; 2003.

37 Acock AC. Working with missing values. J Marriage Fam 2005;67:1012-28.

38 Enders CK, Bandalos DL. The relative performance of full information maximum likelihood estimation for missing data in structural equation models. Struct Equ Modeling 2001;8:430-57

39 Santor DA, Zuroff DC, Ramsay JO, Cervantes P, Palacios J. Examining scale discriminability in the BDI and CES-D as a function of depressive severity. Psychol Assess 1995;7:131-9.

40 Kvaal K, Ulstein I, Nordhus IH, Engedal K. The Spielberger state-trait anxiety inventory (STAI): The state scale in detecting mental disorders in geriatric patients. Int J Geriatr Psychiatry 2005;20:629-34.

41 Tofighi D, MacKinnon DP. RMediation: An R package for mediation analysis confidence intervals. Behav Res Methods 2011;43:692-700.

42 Clark LA, Watson D. Tripartite model of anxiety and depression: Psychometric evidence and taxonomic implications. J Abnorm Psychol 1991;100:316-36.

43 Brown TA, Chorpita BF, Barlow DH. Structural relationships among dimensions of the DSM-IV anxiety and mood disorders and dimensions of negative affect, positive affect, and autonomic arousal. J Abnorm Psychol 1998;107:179-92.

44 Forbes MK, Schniering CA. Are sexual problems a form of internalizing psychopathology? A structural equation modeling analysis. Arch Sex Behav 2013;42:23-34.

45 Hoehn-Saric R, McLeod DR. The peripheral sympathetic nervous system: Its role in normal and pathologic anxiety. Psychiatr Clin North Am 1988;11:375-86. 
46 Thayer JF, Friedman BH, Borkovec TD. Autonomic characteristics of generalized anxiety disorder and worry. Biol Psychiatry 1996;39:255-66.

47 Pfaus JG. Reviews: Pathways of sexual desire. J Sex Med 2009;6:1506-33.

48 Meston CM, Frohlich PF. The neurobiology of sexual function. Arch Gen Psychiatry 2000;57:1012-30.

49 Treadway MT, Zald DH. Reconsidering anhedonia in depression: Lessons from translational neuroscience. Neurosci Biobehav Rev 2011;35:537-55.

50 Derogatis LR, Meyer JK. A psychological profile of the sexual dysfunctions. Arch Sex Behav 1979;8:201-23.

51 Derogatis LR, Rosen R, Leiblum S, Burnett A, Heiman J. The Female Sexual Distress Scale (FSDS): Initial validation of a standardized scale for assessment of sexually related personal distress in women. J Sex Marital Ther 2002;28:31730.

52 Brotto LA, Basson R, Luria M. Original research-psychology: A mindfulness-based group psychoeducational intervention targeting sexual arousal disorder in women. J Sex Med 2008;5:1646-59.

53 Phillips NA. Female sexual dysfunction: Evaluation and treatment. Am Fam Physician 2000;62:127-48.

54 Silverstein RG, Brown AC, Roth HD, Britton WB. Effects of mindfulness training on body awareness to sexual stimuli: Implications for female sexual dysfunction. Psychosom Med 2011;73:817-25. 